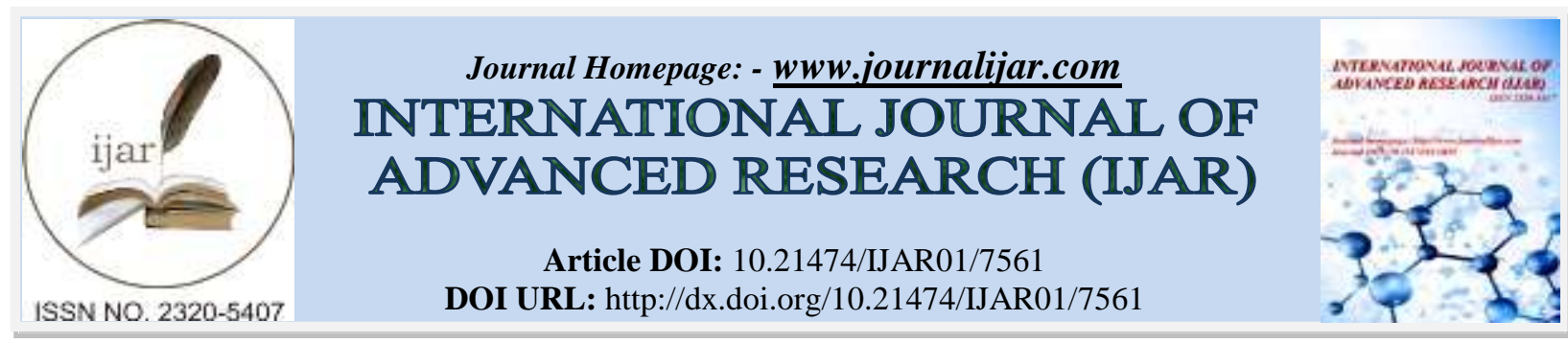

RESEARCH ARTICLE

\title{
PREPARATION AND EVALUATION OF FUNCTIONAL DAIRY-BASED DRINK LIKE MOCHA AGAINST OXIDATIVE STRESS AND LIVER DAMAGE IN RATS.
}

\author{
Ahmed M. Abdel-Salam ${ }^{1}$, Abdel Razik H. Farrag ${ }^{2}$, Medhat, M. Menshawy ${ }^{3}$ and Ahmed H. Zaghloul ${ }^{1}$. \\ 1. Dairy Science Department, National Research Centre, Dokki, Cairo, Egypt. \\ 2. Pathology Department, National Research Centre, Dokki, Cairo, Egypt. \\ 3. Center of Basic Sciences (CBS), Biology Department \& College Pharmaceutical Sciences and Drug \\ Manufacturing, Misr University for Science and Technology, $6^{\text {th }}$ October City, Egypt.
}

\section{Manuscript Info}

(..........................

Manuscript History

Received: 14 June 2018

Final Accepted: 16 July 2018

Published: August 2018

Keywords:-

functional dairy-based drink like mocha, date palm, oxidative stress, liver damage.

\begin{abstract}
Supplementation of phytochemicals and nutrients to functional dairy products are promising amd interest research for human health improvement. Functional dairy-based drink like mocha was pepared by mixing sukkari date fruits and sieved date seeds powder with milk, then its chemical compostion and sensory properties were performed. The hepatoprotective effects of the dairy-based drink to reduce toxic effects of paracetamol-induced liver damage were were studied in male rats. Blood biochemicals analysis and histopathological investigation were performed.The obtained results showed that functional dairy-based drink like mocha had gained accepted degrees for sensory properties. The activities of some serum parmeters and histopathological investigation were improved with manipulation of functional dairybased drink like mocha and paracetamol compared with positive control. Data can be concluded that administration of a functional dairy-based drink like mocha seems to enhance the body defense and contain hepatoprotective factor against oxidative stress and liver damage in rats.
\end{abstract}

Copy Right, IJAR, 2018, All rights reserved.

\section{Introduction:-}

Antioxidant nutrients are currently interest topic to promising research and functional foods application for prevention cancer and cardiovascular disease. Supplementation of antioxidant have demonstrated the association of the prevention of a variety of illnesses and decrease the adverse effects of reactive species, such as reactive oxygen and nitrogen species, on normal physiological function in humans (Panel on Dietary Antioxidants and Related Compounds reports, 2000).

Explore of new drugs and novel therapeutic intervention strategy increasingly includes testing plant extracts and other natural products. Independent of whether extracts are considered or if individual ingredients of a mixture are tested, the pharmacological efficacy of these chemicals needs to be investigated.

For compounds that are assumed to have hepato-protective activity, the model of acetaminophen (APAP) overdose in experimental animals, especially rats and mice, is one of the mainly popular investigational in vivo systems used today (Chen et al., 2009; Wang et al., 2010; Wu et al., 2010; Yuan et al., 2010).

Address:- Dairy Science Department, National Research Centre, Dokki, Cairo, Egypt. 
Acetaminophen (APAP) is a widely used safe and sound analgesic and antipyretic drug. However, an overdose can induce hepatotoxicity and even liver breakdown in animals and humans (Larson et al., 2005). Studies indicated the formation of a reactive metabolite, glutathione depletion and covalent binding to cellular proteins as critical initiating events in the toxicity (Cohen et al., 1997; Nelson, 1990). More studies indicated that the central role of mitochondrial dysfunction, including oxidant stress and peroxynitrite formation, the mitochondrial membrane permeability transition pore opening and nuclear DNA fragmentation as propagation events in APAP-induced cell death in the liver (Jaeschke et al., 2003; Jaeschke and Bajt, 2006).

Fruits of the date palm (Phoenix dactylifera L.) is rich in mineral salts and vitamins (Booij, et al. 1992) and is an excellent material for producing refined sugar, concentrated juice, confectionery pastes and fermentation products (Samarawira, 1983). Dates contain small amounts of vitamins C, B1 (thiamine), B2 (riboflavin) and nicotinic acid (Al-Shahib, and Marshall, 2002). Studies have shown that dates have strong antioxidant (Al-Farsi, et al. 2005), anticancer (Ishurd, et al. 2004) and antiviral (Vayalil, 2002) activities.Milk and dairy products have beneficial properties to improve the human health. It contain many of dairy components including protein, fat, carbohydrate, and minerals which can be used and formulated widely in dairy-based functional foods and (Mattila-Sandholm and Saarela (2003).

The objective of the present study is to prepare and evaluate a functional dairy-based drink like mocha against oxidative stress and liver damage in male rats.

\section{Material and Methods:-}

\section{Date Fruits and milk Samples}

Date fruits (Sukkary type) commonly grown in Qassim region were purchased from the local dates market in Buraidah, Qassim, Saudi Arabia. Also, cow's milk samples were donated from the healthy lactating animals, local farm, Egypt.

Chemicals and pure reagents were purchased from Sigma (Sigma-Aldrich, St. Louis, MO, USA) and Roche Diagnostics (Roche Professional Diagnostics, Rotkreuz, Switzerland.

\section{Animals:}

Male rats (Lab. Animal House, National Research Centre, Cairo, Egypt) of weight 120-150 g were used in this study. The animals were housed in groups of 6 rats in steel cages at $22 \pm 2{ }^{\circ} \mathrm{C}$ with a $12 \mathrm{~h}$ light/dark cycle and allowed to acclimatize for a period of 1 week prior to experimental use. Throughout the experiment, the rats were allowed free access feed (rats dietary pellets prepared by Cairo Company of Oil \& Soap, Egypt) and water.

\section{Preparation and formulation of functional dairy-based drink like mocha}

Fresh sukkary date fruits after removing the seeds were dried and milled. The functional dairy-based drink like mocha was prepared by the mixing $10 \mathrm{~g}$ sukkary date fruits powder and $1 \mathrm{~g}$ sieved date seeds powder with $100 \mathrm{ml}$ milk. The mixture was heated at $85^{\circ} \mathrm{C}$ for $15 \mathrm{~min}$ to kill pathogens, then homogenized and filtered twice and stored at $5 \pm 2{ }^{\circ} \mathrm{C}$. The chemical composition of dates, milk and functional dairy-based drink like mocha samples were performed by the conventional proximate analysis techniques (AOAC, 1990\& 2003). Antioxidant activity of dried sukkary dates and seed powder as well as dates, milk and functional dairy-based drink like mocha were determined according to the method of Brand-Williams et al. (1995). The sensory evaluation of the appearance, color, flavor and overall properties of functional dairy-based drink like mocha was adopted from National Aeronautics and Space Administration (NASA) (1999) using the following scale: (+++) very good, (++) good, (+) acceptable, (-) not acceptable.

\section{Experimental design of dairy-based drink from date and milk to reduce toxic effects of paracetamol-induced liver damage in male rats \\ Twenty-four rats were used and classified into 4 groups (6 rats / group).}

Group I (GI): Rats given saline (1 ml/rat) for one week and kept as control group. Group II (GII): Rats given oral dose of dairy-based drink from date and milk for one week. Group III (G III): Rat given water for 7 days prior to a single dose of paracetamol (2.5g/kg b.wt.) on the eighth day to induce liver damage (Mitra et al., 1998) ) and served as paracetamol-control. Group IV (GIV): Rats were administered of functional dairy-based drink like mocha for 7 days. 
On the eighth day, the animals of this group were given a single dose of paracetamol equivalent to $2.5 \mathrm{~g} / \mathrm{kg}$ body weight (b.wt.). Animal procedures were performed in accordance with the ethics committee of National Research Centre (Egypt) and according to the Guide for the Care and Use of Laboratory Animals of the National Institute of Health. Animals were kept under standard conditions of temperature and humidity along the experimental period.

All the treatments were done by means of a gavageor gastric tube. Twenty-four hours after paracetamol intoxication, the animals were sacrificed by mild ether anesthesia.

Blood was obtained by using the orbital sinus technique of Stone (1954). Blood was collected in dry tube and left to clot, then centrifuged at $3000 \mathrm{rpm}$ for ten min. Serum was separated and freeze at $-20^{\circ} \mathrm{C}$ for the subsequent analyses. After blood samples were obtained, rats were dissected and sections of liver were obtained and prepared for histopathological examinations using light microscopy.

\section{Biochemical analysis}

Serum alkaline phosphatase (ALP) activity was determined according to colorimetric method of Kind and King (1954). Glutamate oxaloacetate transaminase (GOT) and Glutamate pyruvate transaminase (GPT) activities were determined according to the colorimetric method of Reitman \& Frankel (1957). Serum total bilirubin was determined according Jendrassik and Grof (1938). Serum total protein was determined according to the method described by King and Woolton (1956). Serum albumin was estimated according to the method described by Drupt (1974). Serum triglycerides were determined according to Fossati and Prencipe (1982). The enzymatic triglycerides Kit of Bio-Mérieux laboratory reagents and products were used. Serum very low density lipoprotein cholesterol (VLDL-C) was calculated from triglycerides according to Glatter (1984). Serum High Density Lipoprotein Cholesterol (HDL-C) was determined according to Lopez-Virella et al. (1977). The HDL-C kit of Bio-Mérieux laboratory reagents and product was used. Serum high Density Lipoprotein (HDL) was determined according to the method described by Fruchart (1982).Serum Low Density Lipoprotein Cholesterol (LDL-C) was calculated according to Glatter (1984) who reported that:

LDL-C $=$ Total cholesterol $-($ VLDL + HDL-C $)=\mathrm{mg} / \mathrm{dl}$.

\section{Histopathological study}

Liver samples were fixed instantaneously in $10 \%$ formal saline for $24 \mathrm{~h}$. The samples were washed in tap water, dehydrated in ascending grades of ethanol, cleared in xylene, embedded in paraffin wax (melting point 55-60 ${ }^{\circ} \mathrm{C}$ ). Sections of $6 \mu \mathrm{m}$ thicknesses were prepared and stained with Haematoxylin and Eosin (Drury and Wallington, 1980).

\section{Statistical analysis}

Means, standard deviations and coefficient variation of the data from each experimental group were calculated according the method described by Miller and Miller (1992) and Jones et al., (2003).

\section{Results:-}

The chemical composition and sensory properties of the functional dairy-based drink like mocha are shown in Table (1). The mean values of dry matter, protein, carbohydrates, ash and fat were 17.16, 2.76, 10.77, 0.94 and 2.75 respectively.

The sensory properties of functional dairy-based drink like mocha for appearance, and flavor and results were expressed as: (+++) very good, (++) good, $(+)$ acceptable, (-) unacceptable. The obtained results showed that dairybased drink containing milk and date had gained accepted degrees for sensory properties (Table 1).

Antioxidants activity in sukkary date fruit \& seeds, cow milk and functional dairy-based drink like mocha are shown in Fig. (1). the antioxidants activity in milk, functional dairy-based drink like mocha. The antioxidants activity values were increased after adding the sukkary date fruit\& seeds. The antioxidants activity values were 1920 $\& 17760 \mu$ moleTrolex/100g sample in sukkary date fruit\& seeds respectively. The antioxidants activity values were 142 and $1161 \mu$ moleTrolex/L sample in cow milk and dairy-based drink from date respectively. 


\section{Biochemical analysis}

Activities of serum enzymes ALP, GOT and GPT were increased in paracetamol treated rats (G III) compared to control rats and that administrated with functional dairy-based drink like mocha for one week (G I \& G II 2). Moreover, activities of serum enzymes ALP, GOT and GPT were decreased in rats treated with dairy-based drink from date and milk for one week (G IV) compared to paracetamol treated rats (G III) (Table 2).

The mean values of total bilirubin, and total protein, were decreased in paracetamol-induced rats (G III) compared to rats of controls (G I) injected with dairy-based drink from date and milk for one week (G II). The levels of total bilirubin and total protein were increased in functional dairy-based drink like mocha group (G IV) compared to paracetamol-induced rats (G III) Table (2).

Level of total protein (TP), serum albumin (ALB), Total Cholesterol (CHOL) and Serum triglycerides (TG) are shown in Table (4). Concerning to the results of serum albumin, there were not clear changes in serum albumin in paracetamol group (G III) compared with control (G I) and functional dairy-based drink like mocha (G II) groups. In treated group (G IV) there was an increase in levels of serum albumin compared to paracetamol-induced rats (G IV) (Table 3).

Serum very low density lipoprotein cholesterol (VLDL), Serum High Density Lipoprotein Cholesterol (HDL) and Serum Low Density Lipoprotein Cholesterol (LDL) of rat fed on functional dairy-based drink like mocha with paracetamol-induced liver damage compared with negative and positive control (Table 4).

\section{Histopathological Results}

Examination of sections of the liver of control rats shows the normal architecture of the hepatic lobule. The central veins lies at the center of the lobules surrounded by cords of hepatocytes (Fig. 2.A). Control rats shows normal structure of the portal tracts(Fig. 2.B). On the other hand, microscopic examination of liver of rats adminestred the functional dairy-based drink like mocha showed normal normal structure the hepatic lobules and portal tracts(Fig. 2.C, D respectively).

Histopathological investigation of liver of rats given paracetamol showed disturbance of the hepatic lobule. Focal necrosis associated with massive inflammatory cells infiltration, edema, heamorraghe (Fig. 2.F); and congested portal areas that associated with inflammatory cells infiltration(Fig. 2.E).

In case of rats adminestred the functional dairy-based drink like mocha and pracetamol, the results showed normal normal structure ofthe hepatic lobules and portal tracts (Fig.2 .G, H respectively).

\section{Discussion:-}

The non-steroidal analgesic-antipyretic drug, paracetamol, is one of the safest drugs when used in recommended doses, but it is capable if administrated for long periods of producing massive hepatic necrosis on acute over dose or chronic low dose (Bonkovsky, et al. 1994).

Concerning serum biochemical parameters in relation to functions of liver in paracetamol treated group, increases in GPT and GOT levels was found. These results agreed with the previous studies (Sreedhar, et al. 2011). These changes attributed to the development of $\mathrm{N}$-acetyl-pbenzoquineimine, acetaminophen metabolite. This metaboliteis a major cause of hepatocellular damage and centrilobularhepatic necrosis (Diadelis, et al., 1995) and these results supported by histopathological examination of liver in the present work, which showed diffuse Kupffer cellsproliferation between hepatocytes,congestion of sinusoids and ballooning of hepatocytes as described previously (Fouada, and Jresatb, 2012). Increase levels of GPT and GOT may be due to GOT present in both mitochondria and cytosol of hepatocytes, while GPT is found in cytosol only so that when hepatocytes damage release these enzymes into the extracellular fluid and results in increased serum levels of transaminases activity (Kowalczyk, et al. 2003). The liver damage of experimental animals were observed when they are exposed to large doses of toxic agents such as paracetamol (acetaminophen) or carbon tetrachloride and bromobenzene. In this case transaminases are increased after a dose of paracetamol or carbon tetrachloride and bromobenzene (Strubelt et al., 1981 \& Pessayre et al., 1979).

A significant increase in ALP and total bilirubin level might be due implies impairment of bile flow, which can be caused by obstruction of biliary areas(Martin and Friedman, 1998). These findings confirmed by histopathological 
investigation as liver showed distortion of portal areas by fibrous tissue abundance infiltrated with inflammatory cells, expanded in between hepatic parenchyma. In addition, congestion of portal vein and perivascular inflammatory cells and fibrous tissue proliferation in portal area particularly around bile ducts. Increased total bilirubin may be due to failure of normal uptake, conjugation and or excretion by the damaged hepatic parenchyma.

Increasing level of triglyceride agreed with the results of Kanchana and Sadiq (2011). These results might be due to excessive release of triglycerides [46] and/or decreased hepatic release of lipoprotein and increased esterification of free fatty acids (Kanchana and Sadiq, 2011). Also, the decreasing levels of HDLC after overdose paracetamol treatment, agreed previous results of Setty et al., 2007). Overproduction of $\mathrm{H}_{2} \mathrm{O}_{2}$ developed during the cytochrome P450-mediated microsomal metabolism of paracetamol led to disturbance in HDL-C (Rajkapoor, et al. 2008). In contrast, there were non-significant changes in cholesterol and total protein. These results agreed with previous findings of Iweala, and Osundiya (2010).

In conclusions, supplementation of natural antioxidants and nutrients to functional dairy products are promising and interest research for studying the hepatoprotective effects of a dairy-based drink from date and milk to reduce toxic effects of paracetamol-induced liver damage and the obtained results concluded that the coadministration of a therapeutic dairy-based drink and paracetamol had a protective effect and showed that a normal structure of the hepatic lobules and portal tract. In conclusion, dministration of functional dairy-based drink like mocha seems to enhance the body defense and contain hepatoprotective factor against paracetamol-induced liver damage in rats.

Table 1:- Chemical composition and sensory properties of functional dairy-based drink like mocha

\begin{tabular}{|l|l|}
\hline & Functional dairy-based drink like mocha \\
\hline pH & 6.73 \\
\hline Dry matter & 17.16 \\
\hline Proteins & 2.76 \\
\hline Carbohydrates & 10.77 \\
\hline Ash & 0.94 \\
\hline Fat & 2.75 \\
\hline Appearance & ++ \\
\hline Odor & +++ \\
\hline Texture & ++ \\
\hline Flavor & +++ \\
\hline Overall & +++ \\
\hline \multicolumn{2}{|l|}{$(+++)$ very good, $(++)$ good, $(+)$ acceptable, $(-)$ unacceptable } \\
\hline
\end{tabular}

Table 2:- Level of GOT, GPT, TBIL and ALP of rat fed on a functional dairy-based drink like mocha with paracetamol-induced liver damage

\begin{tabular}{|l|l|l|l|l|l|l|l|l|l|l|l|l|}
\hline & \multicolumn{3}{l}{ GOT(U/L) } & \multicolumn{2}{l|}{ GPT (U/L) } & \multicolumn{2}{l|}{ TBIL $(\mu \mathrm{mol} / \mathrm{L})$} & \multicolumn{2}{|c|}{ ALP (U/L) } \\
\cline { 2 - 15 } & Mean & SD & C.V. & Mean & SD & C.V. & Mean & SD & C.V. & Mean & SD & C.V. \\
\hline GI & 166.75 & 2.4 & 1.44 & 74.5 & 3.69 & 4.95 & 0.79 & 0.12 & 15.19 & 32.5 & 2.08 & 6.4 \\
\hline G II & 136 & 3.95 & 2.90 & 29.33 & 5.08 & 17.32 & 0.63 & 0.09 & 14.29 & 35.83 & 3.84 & 10.72 \\
\hline G III & 229.33 & 3.99 & 1.74 & 90.83 & 12.08 & 13.30 & 0.59 & 0.15 & 25.42 & 40.16 & 4.26 & 10.61 \\
\hline G IV & 165.01 & 1.9 & 1.15 & 26.6 & 1.51 & 5.68 & 0.65 & 0.07 & 10.77 & 35 & 4.41 & 12.60 \\
\hline
\end{tabular}

$\mathrm{SD}=$ standard deviation; C.V. = coefficient of variation (\%)

Table 3:- Level of TP, ALB, CHOL and TG of rat fed on a functional dairy-based drink like mocha with paracetamol-induced liver damage

\begin{tabular}{|c|c|c|c|c|c|c|c|c|c|c|c|c|}
\hline & \multicolumn{3}{|c|}{$\mathrm{TP}(\mathrm{g} / \mathrm{L})$} & \multicolumn{3}{|c|}{ ALB $(\mathrm{g} / \mathrm{L})$} & \multicolumn{3}{|c|}{ CHOL $(\mathrm{mg} / \mathrm{dL})$} & \multicolumn{3}{|c|}{$\mathrm{TG}(\mathrm{mg} / \mathrm{dL})$} \\
\hline & Mean & SD & C.V. & Mean & SD & C.V. & Mean & SD & C.V. & Mean & SD & C.V. \\
\hline GI & 6.37 & 0.25 & 3.92 & 2.65 & 0.2 & 7.55 & 34.1 & 1.1 & 3.23 & 64.4 & 3.22 & 5.00 \\
\hline G II & 5.81 & 0.23 & 3.96 & 2.58 & 0.4 & 15.50 & 23.78 & 0.8 & 3.36 & 66.05 & 5.2 & 7.87 \\
\hline G III & 4.13 & 0.24 & 5.81 & 2.88 & 0.3 & 10.42 & 33.98 & 0.6 & 1.77 & 79.7 & 0.2 & 0.25 \\
\hline G IV & 6.46 & 0.21 & 3.25 & 3.36 & 0.24 & 7.14 & 36.54 & 0.62 & 1.70 & 67.96 & 4.4 & 6.47 \\
\hline
\end{tabular}

$\mathrm{SD}=$ standard deviation; C.V. = coefficient of variation (\%) 
Table 4:- Level of VLDL, HDL and LDL of rat fed on a functional dairy-based drink like mocha with paracetamolinduced liver damage

\begin{tabular}{|l|l|l|l|l|l|l|l|l|l|}
\hline & \multicolumn{4}{|l|}{ HDL (mg/dL) } & \multicolumn{2}{l|}{ LDL (mg/dL) } & \multicolumn{2}{l|}{ VLDL (m) } \\
\cline { 2 - 10 } & Mean & SD & C.V. & Mean & SD & C.V. & Mean & SD & C.V. \\
\hline GI & 41.85 & 4.08 & 9.75 & 20.62 & 0.73 & 3.54 & 12.87 & 0.65 & 5.05 \\
\hline G II & 38.05 & 9.11 & 23.94 & 24.78 & 1.5 & 6.05 & 13.21 & 1.01 & 7.65 \\
\hline G III & 36.48 & 5.88 & 16.12 & 36.85 & 0.4 & 1.09 & 13.53 & 0.87 & 6.43 \\
\hline G IV & 36.61 & 1.68 & 4.59 & 9.69 & 0.35 & 3.61 & 13.61 & 0.88 & 6.47 \\
\hline
\end{tabular}

$\mathrm{SD}=$ standard deviation; C.V. = coefficient of variation $(\%)$
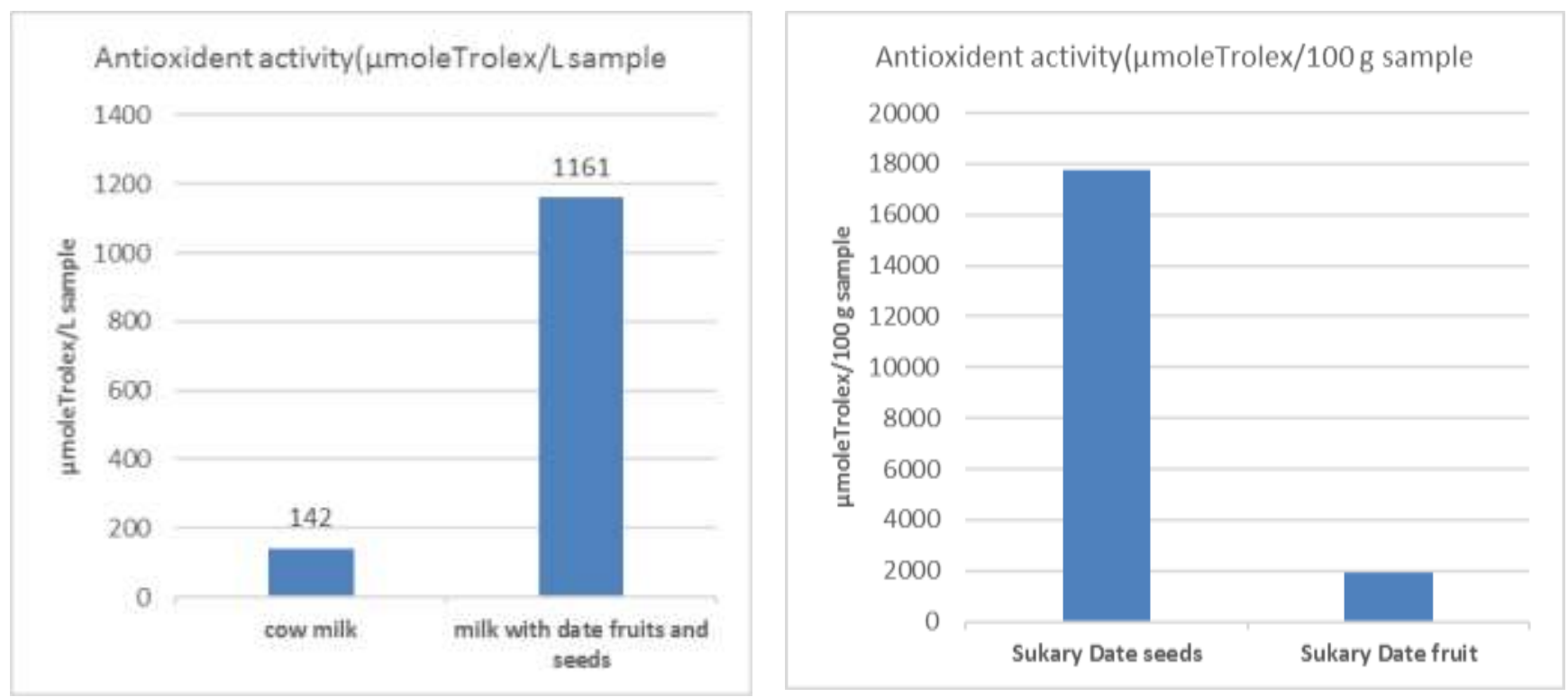

Fig. 1:- Antioxidants activity in sukkary date fruit \& seeds, cow milk and a functional dairy-based drink like mocha. 

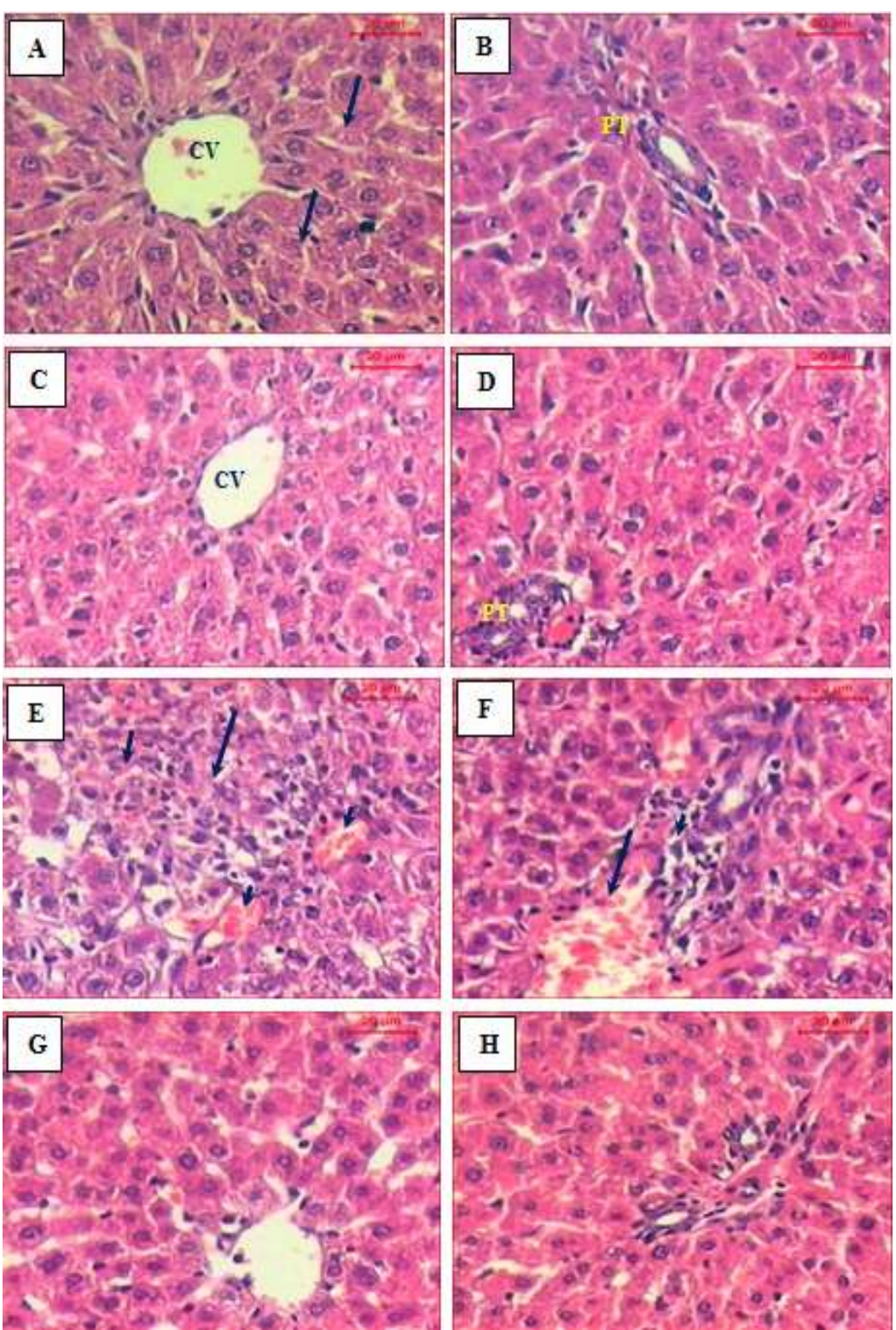

Fig. 2:- Sections of the liver of A): control rat showing the normal architecture of the hepatic lobule. The central vein $(\mathrm{CV})$ lies at the center of the lobulesurrounded by cords of hepatocytes (arrows), B): control rat showing normal structure of the portal tract (PT), C,D): rat adminestred the extract showing normal normal structure the hepatic lobule and portal tract, respectively, E): rat given paracetamol showing disturbance of the hepatic lobule.

Notic focal necrosis associated with massive inflammatory cell infiltration (arrows), edema (arrowhead) and heamorraghe (short arrow),F):rat given paracetamol showing congested portal areas (arrows) that associated with inflammatory cell infiltration (arrowhead), andG, H): rat adminestred of functional dairy-based drink like mocha and pracetamol showing normal normal structure the hepatic lobule and portal tract, respectively, $(\mathrm{H} \& \mathrm{E}$, scale bar: 20 $\mu \mathrm{m})$. 


\section{References:-}

1. Al-Farsi M., Alasalvar, C. Morris, A. Baron, M. Shahidi, F. Comparison of antioxidant activity, anthocyanins, carotenoids, and phenolics of three native fresh and sun-dried date (Phoenix dactylifera L.) varieties grown in Oman, J. Agric. Food Chem. 53 (2005) 7592-7599.

2. Al-Shahib, W. Marshall, J.R. Dietary fibre content of dates from 13 varieties of date palm Phoenix dactylifera, Int. J. Food Sci. Technol. 37 (6) (2002) 719-722.

3. AOAC. Official methods of analysis of the Association of Official Analytical Chemists. 15th edition. Washington, DC, Association of Official Analytical Chemists.1990.

4. AOAC International. Official methods of analysis of AOAC International. 17th edition. 2nd revision. Gaithersburg, MD, USA, Association of Analytical Communities.2003.

5. Bonkovsky, H.L., Kane, R.E., Jones, D.P., Galinsky, R.E., Banner, R. 1994. Acute hepatic and renal toxicity from low doses of acetaminophen in the absence of alcohol abuse or malnutrition: evidence for increased susceptibility to drug toxicity due to cardiopulmonary and renal insufficiency. Hepatology 19(5): 1141-1448.

6. Booij, I. Piombo, G. Risterucci, J.M. Coupe, M. Thomas, D. Ferry, M. Study of the chemical composition of dates at various stages of maturity for varietals characterization of various of date palm cultivars (Phoenix dactylifera L.), Fruit Paris 47 (1992) 667-677. Samarawira, I. Date palm, potential source for refined sugar, Econ. Botany 37 (1983) 181-186.

7. Chen X, Sun CK, Han GZ, et al. Protective effect of tea polyphenols against paracetamol induced hepatotoxicity in mice is significantly correlated with cytochrome P450 suppression. World J Gastroenterol 2009; 15:1829-35.

8. Cohen SD, Khairallah EA. Selective protein arylation and acetaminophen-induced hepatotoxicity. Drug Metab Rev. 1997; 29:59-77

9. Diadelis, R., Jan, N.M., Commandeur, E.D., Nic, P.E.,Vermeulen. 1995. Mechanism of protection of Lobenzarit against paracetamol-induced toxicity in rat hepatocytes Environmental Toxicology and Pharmacology Section 293: 300.

10. Drupt, F., 1974. Colorimetric method for determination of albumin. Pharm. Biol., 1, 777- 779s.

11. Drury RAB, Wallington EA. Preparation and fixation of tissues. In: Drury RAB, Wallington EA, editors. Carleton's Histological Technique. 5. Oxford: Oxford University Press; 1980. pp. 41-54.

12. Fossati, P. and Prencipe, L. (1982) Serum Triglycerides Determined Colorimetrically with an Enzyme that Produces Hydrogen Peroxide. Clinical Chemistry, 28, 2077-2080.

13. Fouada, A.A., Jresatb, 1. 2012. Hepatoprotective effect of coenzyme Q10 in rats with acetaminophen toxicity. Environmental Toxicology and Pharmacology 33(2): 158-167.

14. Fruchart, G. C., 1982. LDL-Cholesterol Determination after Separation of Low Density Lipoprotein. Rev. Fr. Des. Laboratories, 103: 7- 117.

15. Glatter TR. Hyperlipidemia. What is 'normal,' who should be treated and how. Postgrad Med 1984;76:49-55, 58-9.

16. Ishurd, O. Zgheel, F. Kermagi, A. Flefla, M. Elmabruk, M. Antitumor activity of beta-d-glucan from Libyan dates, J. Med. Food 7 (2004) 252-255.

17. Iweala, E.E.J., Osundiya, A.O. 2010. Biochemical, Haemayological and Histological Effects of Dietary Supplementation with leaves of Gnetum africanum Welw on Paracetamol induced Hepatotoxicity in rats. International Journal of Pharmacology 6(6): 872-879.

18. Jaeschke H, Bajt ML. Intracellular signaling mechanisms of acetaminophen-induced liver cell death. Toxicol. Sci. 2006;89:31-41

19. Jaeschke H, Knight TR, Bajt ML. The role of oxidant stress and reactive nitrogen species in acetaminophen hepatotoxicity. Toxicol. Lett. 2003;144:279-288.

20. Jendrassik, L. and Grof, P (1938). Colorimetric Method of Determination of bilirubin. Biochem Z. 297:81-82.

21. Jones, S.P., Blackwell, A., Burnett, M. (2003). A user-centred approach to functions in Excel. In: ICFP. ACM (2003)

22. Kanchana, N., Sadiq, A.M. 2011. Hepatoprotective effect of Plumbago zeylanica on paracetamol induced liver toxicity in rats. International Journal of Pharmacy and Pharmaceutical Sciences 3(1): 0975-1491.

23. KIND, P. R. N., AND KIng, E. J. (1954). Estimation OF Plasma PhOSPHATASE BY DETERMINATION OF HYDROLYSED PHENOL WITH AMINOANTIPYRINE. J. CLIN. PATH., 7, 322-326.

24. King, E. J. and Woolton, I. D. P. (1956): Microanalysis in Medical Biochemistry, p. 91, London,]. \& A. Churchill Ltd. 
25. Kowalczyk, E., Kopff, A., Fijalkowski, P., Kopff, M., Niedworok, J., Smigielski, J., Blaszczyk, J., Kedziora, J., Tyslerowicz, P. 2003. Effect of anthocyanins on selected biochemical parameters in rats exposed to cadmium. Acta Biochimica Polonica 50(2): 543-601.

26. Larson AM, Polson J, Fontana RJ, Davern TJ, Lalani E, Hynan LS, Reisch JS,SchiødtFV, Ostapowicz G, Shakil AO, Lee WM; Acute Liver Failure Study Group Acetaminophen-induced acute liver failure: results of a United States multicenter, prospective study.Hepatology. 2005; 42(6):1364-72.

27. Latimer KS, Mahaffey EA, Prasse KW, eds. Duncan \& Prasse's 2003. Veterinary Laboratory Medicine: Clinical Pathology, 4th ed. Ames, Iowa: Iowa State University Press.

28. Lopez-Virella MF, Stone P, Ellis S, Colwell JA (1977). Cholesterol determination in high-density lipoproteins separated by three different methods. Clin. Chem., 23: 882-884.

29. Martin, P., Friedman, L.S. 1998. Assessment of liver function and diagnostic studies In. Handbook of liver Disease. Ed. Friedman LS, Keeffe EB and Maddery WC. London, Churchill, Livingstone.

30. Mattila-Sandholm T. and Saarela (2003). M. Functional dairy products,eds. Woodhead Publishing Ltd, Abington Hall, Abington, Cambridge CB21 6AH, England)

31. Miller JC and Miller JN. ( 1992), Statistics for Analytical Chemistry. New York, NY USA: Ellis Horweed

32. Mitra SK, Venkataranganna MV, Sundaram R, Gopumadhavan S. Protective effect of HD-03, a herbal formulation against various hepatotoxic agents in rats J. Ethnopharmacol. 1998; 63:18-186.

33. N.A,S,A, (1999). Space Food and Nutrition. An Educator's Guide. Nutritional BiochemistryLaboratoryJohnson Space Center, Houston TX, USA.

34. N.A.S.A. Space Food and Nutrition An Educator's Guide.Nutritional Biochemistry Laboratory-Johnson Space CenterHouston, (1999). TX. USA.

35. Nelson, S.D., 1990. Molecular mechanisms of hepatotoxicity caused by acetaminophen. Semin. Liver Dis. 10, 267-278

36. Panel on Dietary Antioxidants and Related Compounds (2000). Dietary reference intakes for vitamin C, vitamin E, selenium, and carotenoids. Washington, DC: National Academy Press; 2000.

37. Pessayre D, Dolder A, Artigon JY, Wandscheer JC, Descatoire V, Degott C, Benhamon JP.(1979).Effect of fasting on metabolite-mediated hepatotoxicity in the rat. Gastroenterology 1979; 77:264-71.

38. Rajkapoor, B.; Venugopal, Y.; Anbu, J.; Harikrisshnan, N.; Gobinath, M. andRavichandran, V. 2008. Protective effect of Phyllanthuspolyphylluson acetaminophen induced hepatotoxicity in rats. Pakistan. J. Pharm. Sci., 21(1): 57-62.

39. Reitman S \& Frankel S. A colorimetric method for the determination of serum glutamic oxalacetic and glutamic pyruvic transaminases. Amer. J. Clin. Pathol. 28: 56-63, 1957.

40. Sanchez-Moreno, C., J.A. Larrauri and F. Saura-Calixto, 1998. A procedure to measure the antiradical efficiency of polyphenols. J. Sci. Food Agric., 76: 270-276.

41. Setty, S.R., Quereshi, A.A., Swamy, A.H., TusharPatil, T., Prakash, T., Prabhu, K., Gouda, A.V. 2007.Hepatoprotective activity of Calotropisprocera flowers against paracetamol-induced hepatic injury in rats. Fitoterapia (78):451-454.

42. Snedecor, G W and Cochran, W G. (1980). Statistical methods. $7^{\text {th }}$ edition, Iowa State University Press, Ames, Iowa.

43. Sreedhar, V., Nath, L.K., Nath, M.S., RajaSekhar, K.K., Shankarananth, V. 2011. Hepatoprotective Activity of Vitextrifoliata roots against Paracetamol-Induced Hepatic Injury in rats. Journal of Pharmacy Research 4(2): 551-553.

44. Stone, SH. Method for obtaining venous blood from the orbital sinus of the rat or mouse. Science, $1954 ; 119$ (3081): 100 .

45. Strubelt O, Dost-Kempf E, Siegers CP, Younes M, Völpel M, Preuss U,Dreckmann JG. (1981). The influence of fasting on the susceptibility of mice to hepatotoxic injury. Toxicol Appl Pharmacol 1981; 60:66-77.

46. Vayalil, P.K. Antioxidant and antimutagenic properties of aqueous extract of date fruit (Phoenix dactylifera L. Arecaceae), J. Agric. Food Chem. 50 (2002) 610-617.

47. Wang AY, Lian LH, Jiang YZ, Wu YL, Nan JX. Gentiana manshurica Kitagawa prevents acetaminopheninduced acute hepatic injury in mice via inhibiting JNK/ERK MAPK pathway. World J Gastroenterol 2010;16:384-91.

48. Wu YL, Jiang YZ, Jin XJ, Lian LH, Piao JY, Wan Y, et al. Acanthoic acid, a diterpene inAcanthopanax koreanum, protects acetaminophen-induced hepatic toxicity in mice. Phytomedicine 2010;17:475-479.

49. Yuan HD, Jin GZ, Piao GC. Hepatoprotective effects of an active part from Artemisiasacrorum Ledeb. against acetaminophen-induced toxicity in mice. J Ethnopharmacol; 2010;127:528-33. 